\title{
Investigating the Removal Ethidium Bromide from Aqueous Solutions using Activated Persulfate in Electrochemical Process
}

\author{
Mohammad Reza Samarghandi (PhD) ${ }^{1}$, Yousef Poureshgh (MSc) ${ }^{2}$, Mohammad Vanaei \\ Tabar (MSc) $)^{3}$, Zahra Rahmani (MSc) ${ }^{2}$, Sattar Ahmadi (MSc) $)^{4,5, *}$ \\ ${ }^{I}$ Department of Environmental Health Engineering and Research Center for Health Science, School of Health, Hamadan \\ University of Medical Sciences, Hamadan, Iran \\ ${ }^{2}$ PhD Student of Environmental Health Engineering, School of Public Health, Hamadan University of Medical Sceinces, \\ Hamadan, Iran \\ ${ }^{3}$ Student Research Center, Hamadan University of Medical Sciences, Hamadan, Iran. Operation Expert of ABFAR \\ Hamadan, Iran \\ ${ }^{4}$ Student Research Center, Hamadan University of Medical Sciences, Hamadan, Iran \\ ${ }^{5}$ Quality control experts and laboratory affairs, Ardabil Province Water and Wastewater Company, Ardabil, Iran
}

* Corresponding Author: Sattar ahmadi, Student Research Center, Hamadan University of Medical Sceinces, Hamadan, Iran.Email: Sattarahmadi66@gmail.com

\section{Received: $14 / 01 / 2017$ \\ Accepted: 20/11/2017 \\ How to Cite this Article: Samarghandi MR, Poureshgh Y, Vanaei Tabar M, Rahmani $\mathrm{Z}$, Ahmadi S. Investigating the Removal Ethidium Bromide from Aqueous Solutions using Activated Persulfate in Elec- trochemical Process. Pajouhan Scientific Journal. 2018; 16(2): 1-10. DOI: $10.21859 /$ psj.16.2.1}

\section{Abstract}

Background and Objective: Ethidium bromide is known as a Mutagenic substance that due to some of its characteristics including accumulative property in organism bodies, can cause major environmental problems. In this research, we studied the effect of activated persulfate by electrochemical method in removal of ethidium bromide in laboratory conditions.

Materials and Methods: In this experimental study, which was conducted in a laboratory pilot, used from a discontinued reactor with one liter capacity that equipped with four electrodes of iron as a monopolar connection? Entrance voltage (Amper), initial concentration of persulfate, $\mathrm{pH}$, reaction time and initial concentration of Ethidium bromide was investigated. The remaining concentrations of Ethidium bromide was determined by using spectrophotometry at a wavelength of $480 \mathrm{~nm}$.

Results: The results of this study showed that the initial $\mathrm{pH}$, entrance voltage and the initial concentrations of persulfate have a significant effect on the removal of pollutants, also the maximum removal rate occurred in acidic $\mathrm{pH}$. By increasing the concentration of persulfate and the entrance voltage, the efficiency of the process increased and by increasing the initial concentration of Ethidium bromide, the efficiency of the process decreased. So that in appropriate conditions obtained from the experiment, $93.2 \%$ of the pollutant was removed in 40 minutes and $100 \%$ in 60 minutes. Also removal efficiency for COD at optimal time was $72 \%$.

Conclusion: The results showed that by using activated persulfate in electrochemical process with iron electrodes can be an appropriate method to remove the pollutants in refineries and aqueous solutions.

Keywords: Aqueous Solution; Electro/Persulfate; Ethidium Bromide; Iron Electrode 


\title{
بررسى حذف اتيديوم برومايد از محيط آبى با استفاده از يرسولفات فعالشده به روش الكتروشيميايى
}

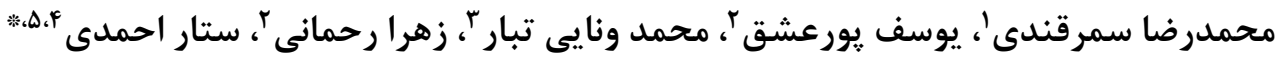

' استاد كروه مهندسى بهداشت محيط و عضو مركز تحقيقات علوم بهداشتى، دانشكده بهداشت دانشعاه علوم يزشكى همدان، همدان، ايران

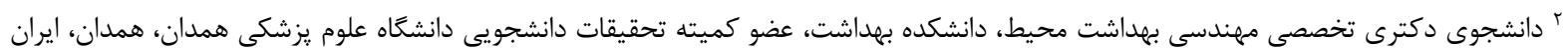

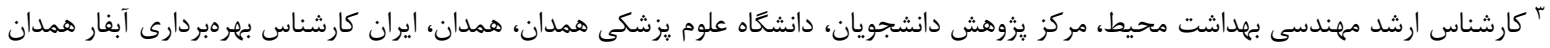

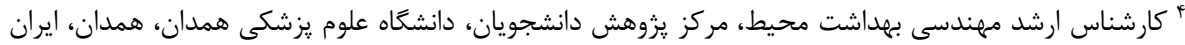

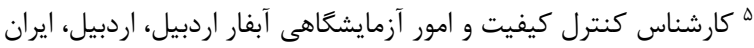

* نويسنده مسئول: ستار احمدى، مركز يزوهش دانشجويان، دانشحاه علوم يزشكى همدان، همدان، ايران.

ايميل: Sattarahmadi66@gmail.com

\begin{tabular}{|c|c|}
\hline 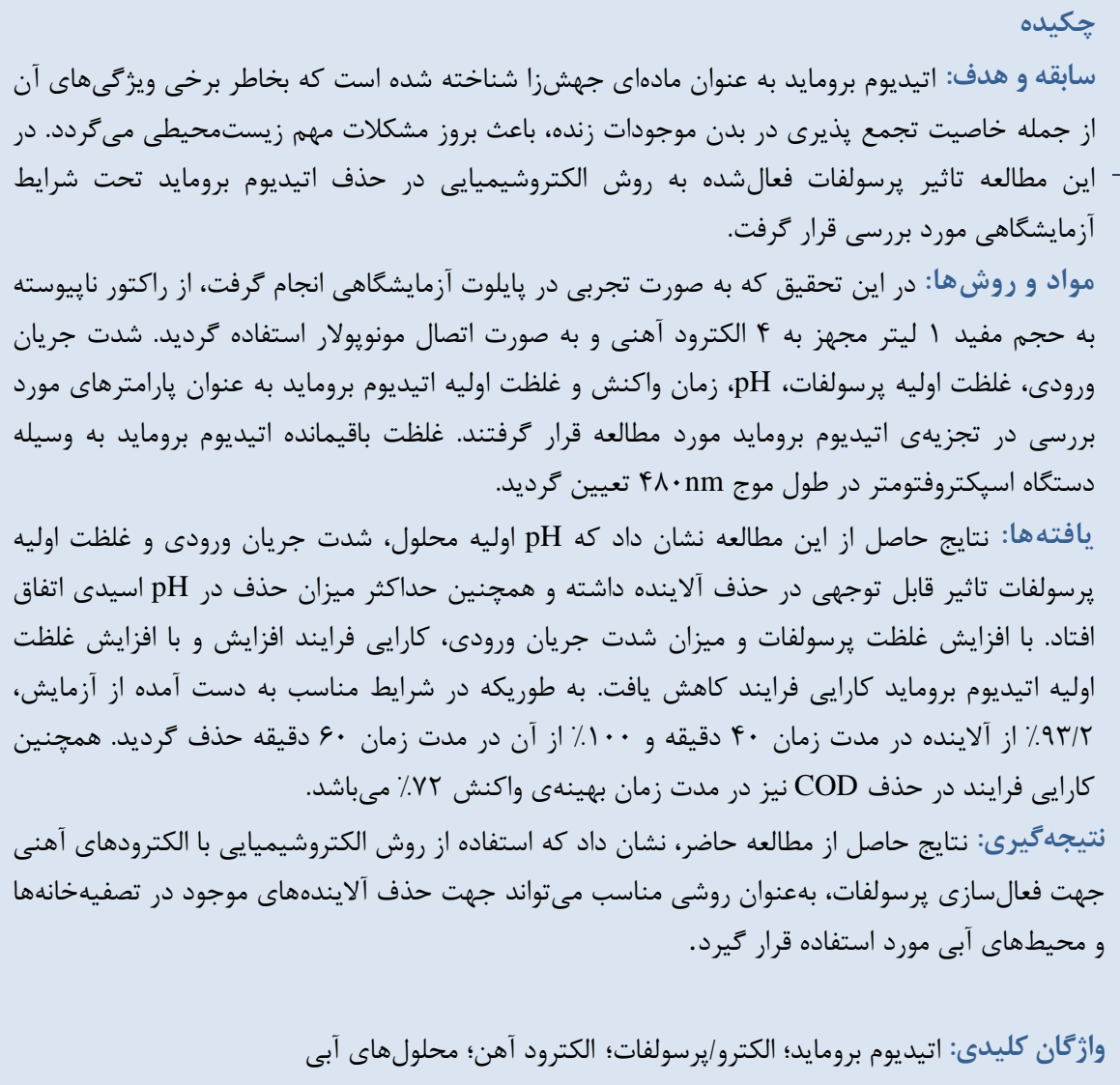 & 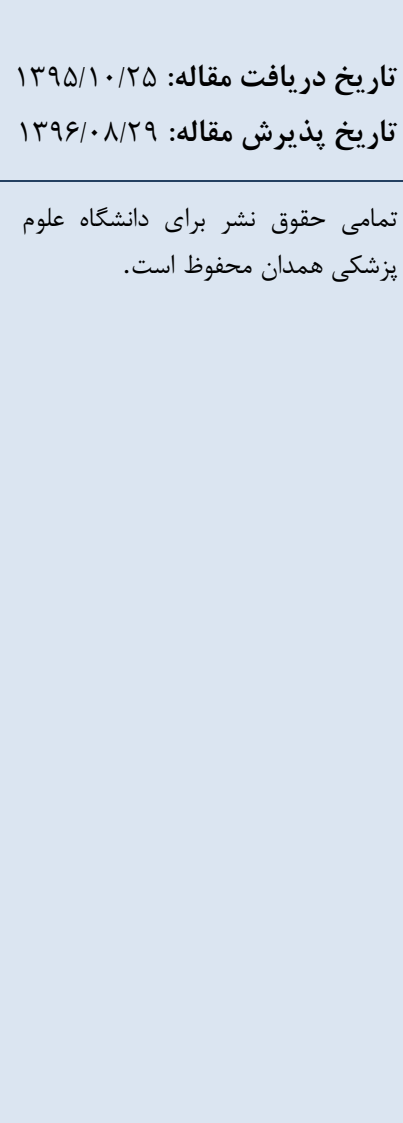 \\
\hline
\end{tabular}

مقلدمه

وجود دارد كه كسترهاى از زائدات جامد و مايع را ايجاد مى كند.

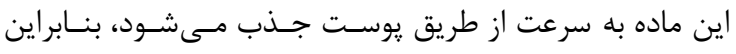
ممانعت از تماس با اين ماده شيميايى بسيار مهرم مى بـ باشد. ايسن

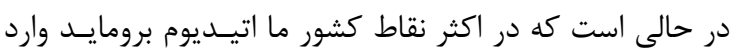

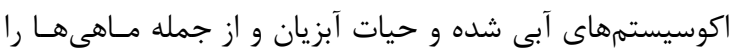

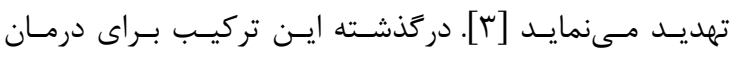

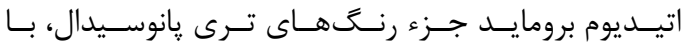

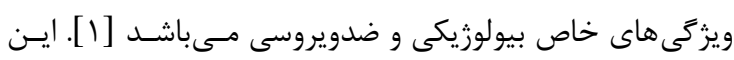

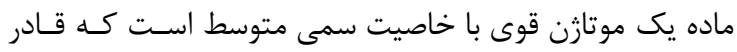

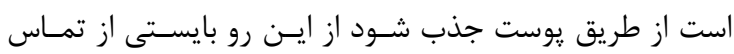

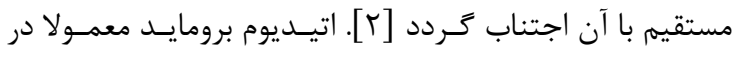

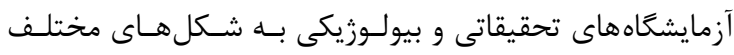




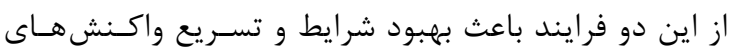

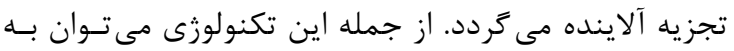

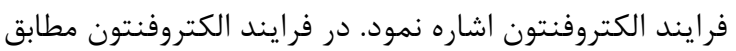

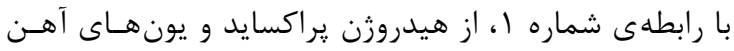
دو ظرفيتى كه بهصورت الكتريكى از الكترودهاى آهن توليد

شدهاند، استفاده مى شود [9]

$\mathrm{Fe}^{2+}+\mathrm{H}_{2} \mathrm{O}_{2} \rightarrow \mathrm{Fe}^{3+}+\mathrm{OH}^{-}+\mathrm{OH}^{\circ}$

$\mathrm{H}_{2} \mathrm{O}_{2}+\mathrm{Fe}^{3+} \rightarrow \mathrm{Fe}^{2+}+\mathrm{H}_{2} \mathrm{O}^{\circ}+\mathrm{H}^{+}$

در سال هاى اخير استفاده از ماده اكسيدكننده يرسولفات

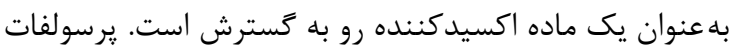
آنيون غيرانتخابى، محلول و در دماى اتاق نسبتا پايدار بوده و

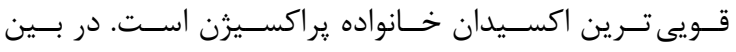
اكسيد كننده هاى قوى، :رسولفات و راديكال سولفات ناشسى از از

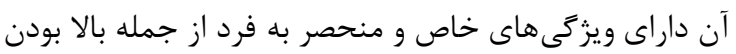

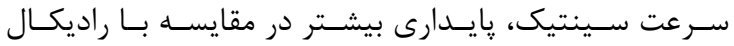

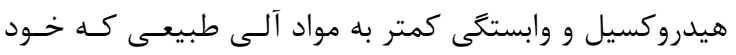

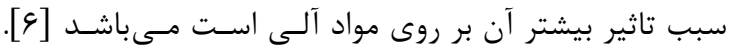

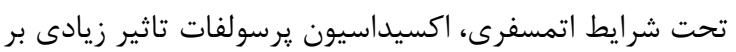

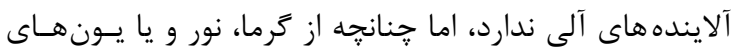

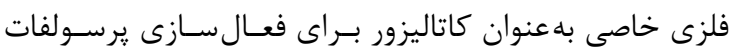

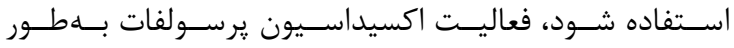
جشمخيرى افزايش مى يابد [ • []. در بين موارد فوق اسـتفادهاه

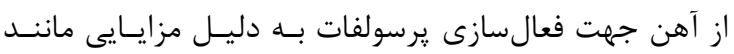

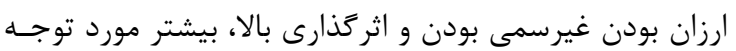

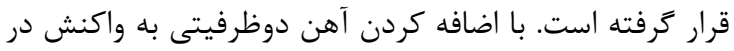

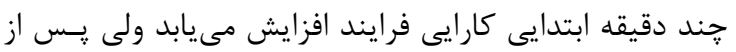

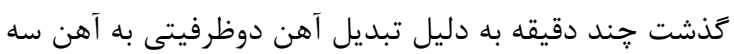

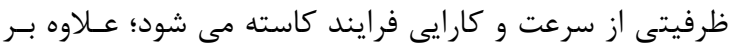

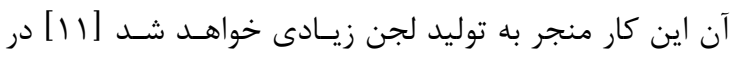

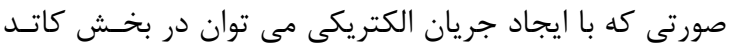

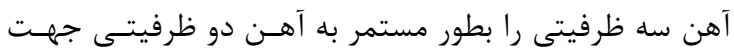

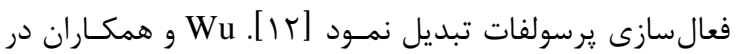

ترييانوزومويس توسط داميزشكان مورد استفاده قرار مى گرفــ؛

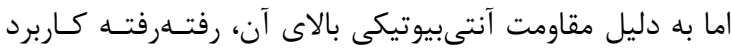

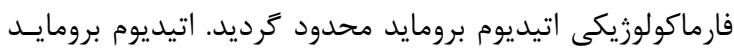

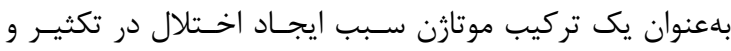

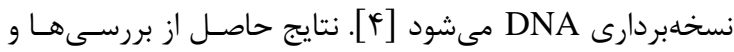

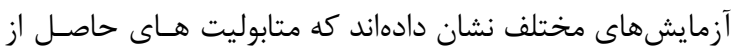

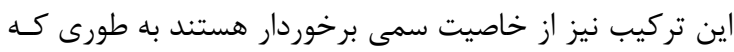

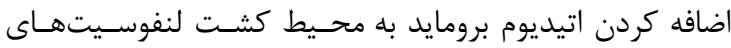

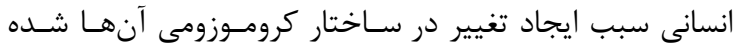

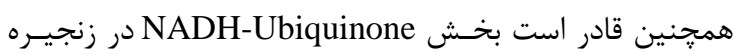
تنفسى رادر ميتوكندرى مهار نمايد [ه].

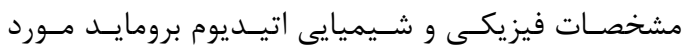

مطالعه در جدول ا نشان داده شده است. تاكنون روش هاى مختلفى براى حذف اتيديوم برومايد از إن إندان

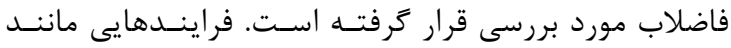

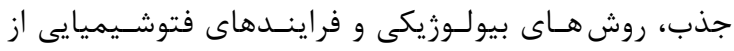

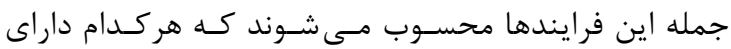

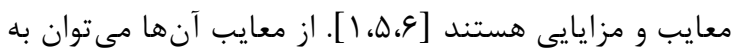

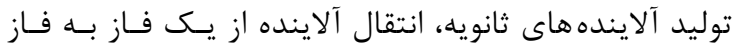

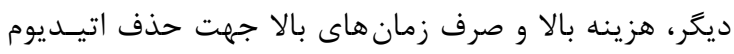

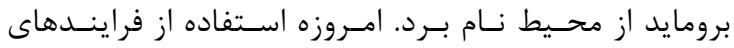

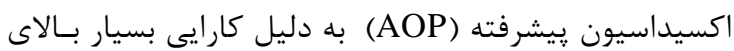

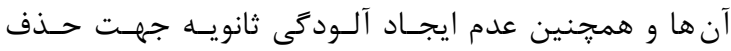

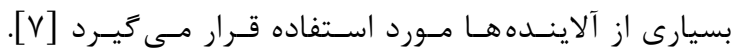

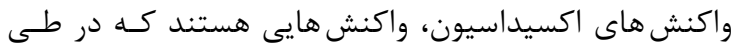

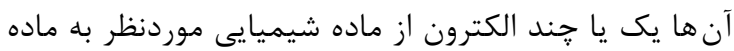

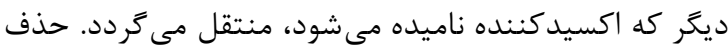

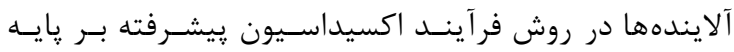

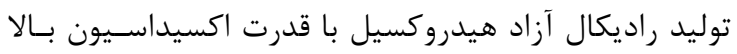

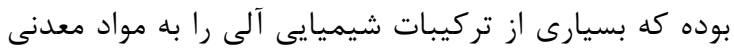

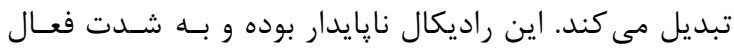

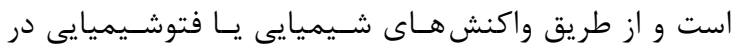

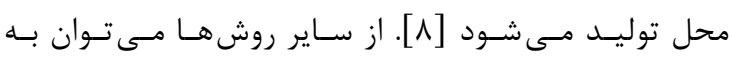

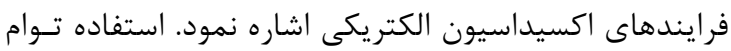

جدول ا: مشخصات فيزيكى و شيميايى اتيديوم برومايد [1]

مشخصات فيز يكى مشخصات شيميايى


مواد مورد نياز براى انجــام ايـن مطالعـهـ از جملـه اتيـديوم

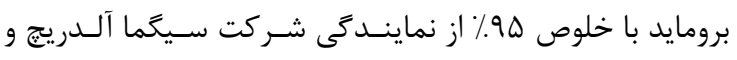

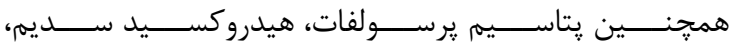

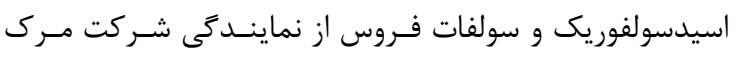
آلمان خريدارى شدند. دسـتخاههـاى مورداسـتفاده نيـز شـامل

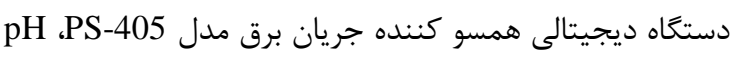

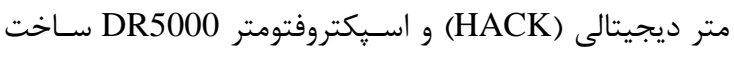
كشور آمريكا بودند.

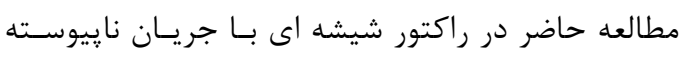

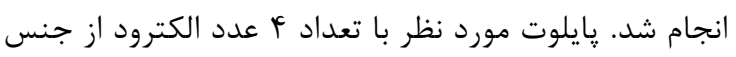

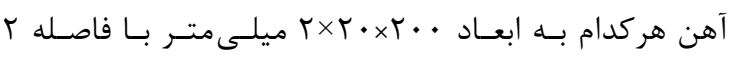

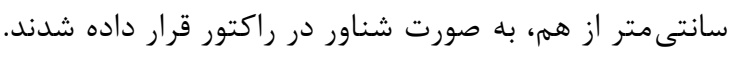

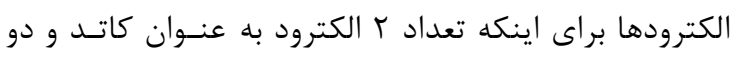

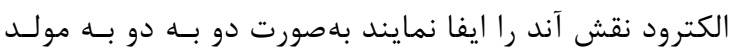

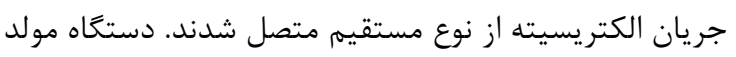

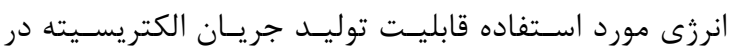

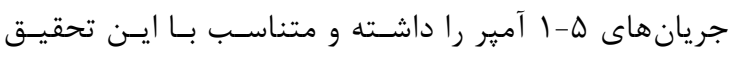

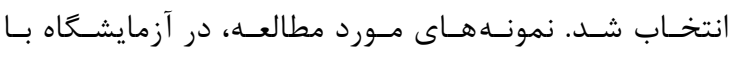

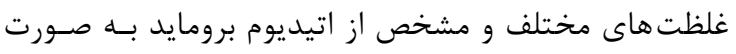

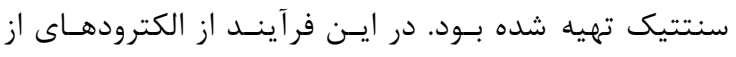

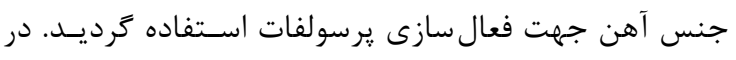

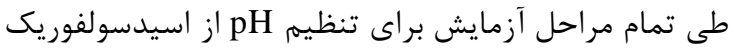

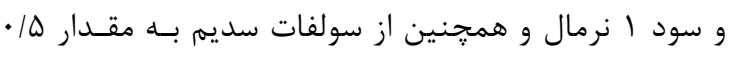
كرم در ليتر جهت بهبود خاصيت يونى محلول استفاده شد. در شكل ا شمايى از راكتور مورد استفاده آورده شده است.

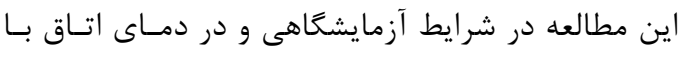

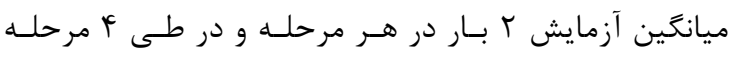

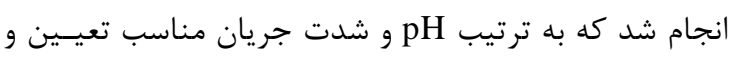

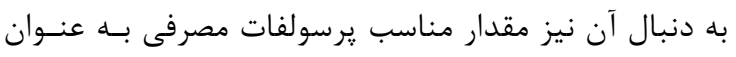

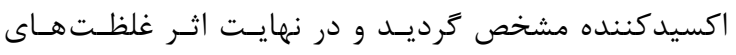

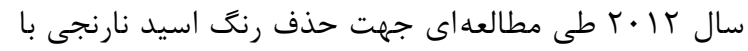

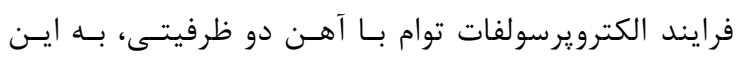

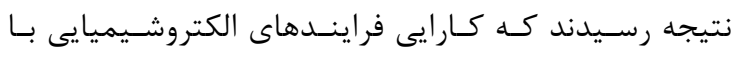

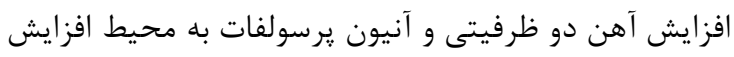

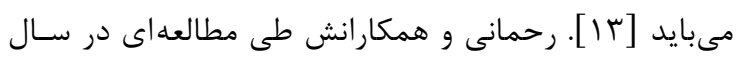

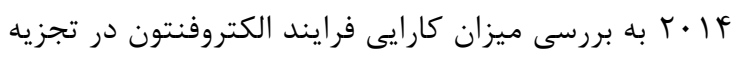

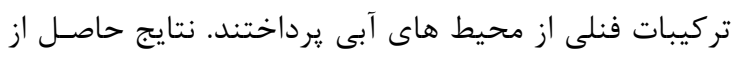

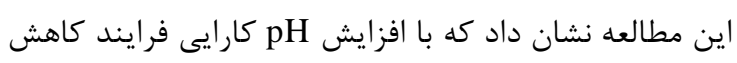

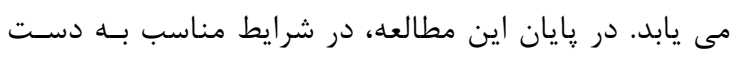

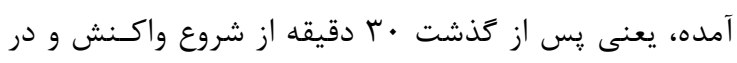

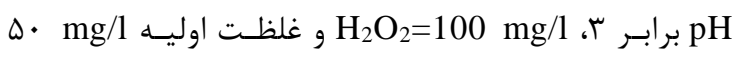

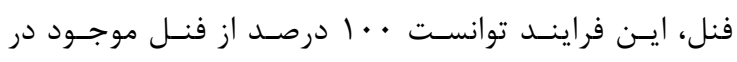

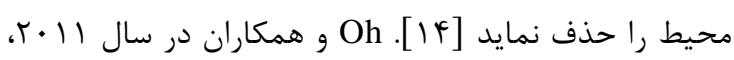

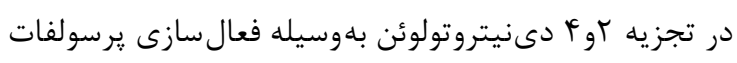

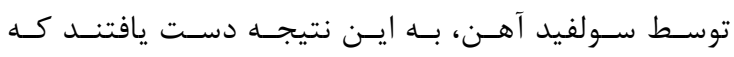

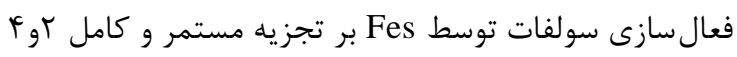

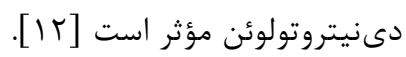

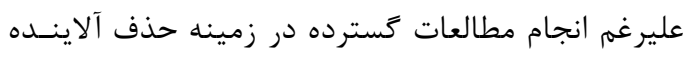

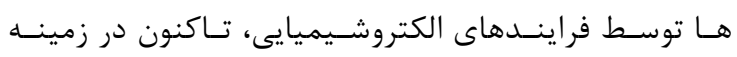

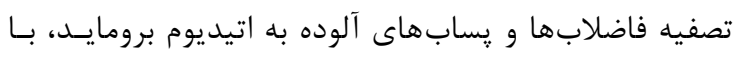

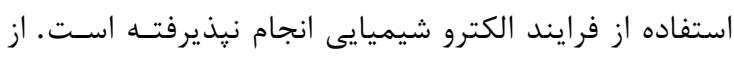

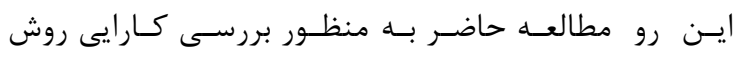

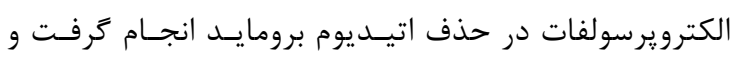

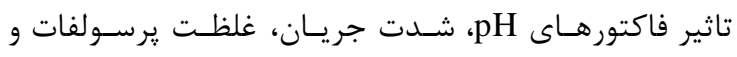
غلظتهاى مختلف آلاينده انجام شده است.

\section{مواد و روشها}

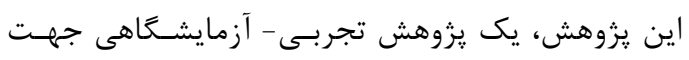

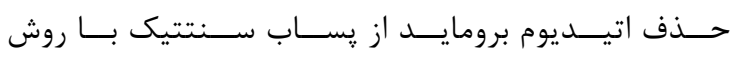
الكتروشيميايى مىباشد.

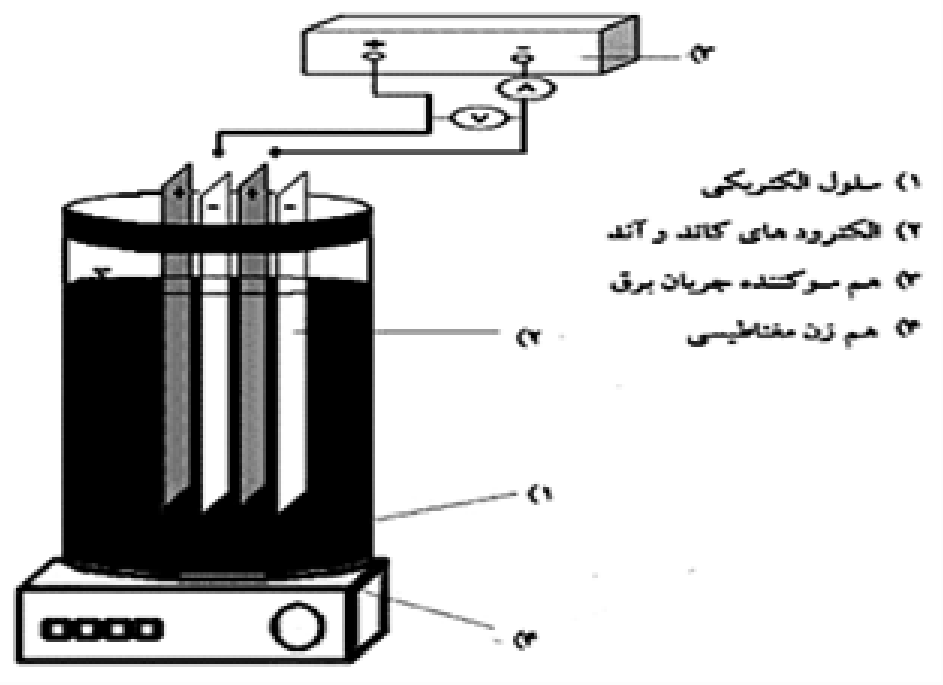

شكل ا: شماتيك راكتور آزمايش 
در اين فرمول X(\%) راندمان حذف، C

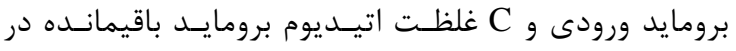

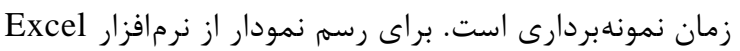

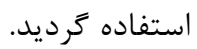

\section{بافته ها تأثير تغييرات pH بر كارائ فرايند}

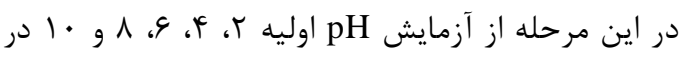

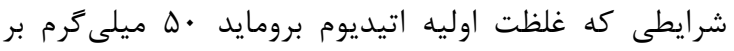

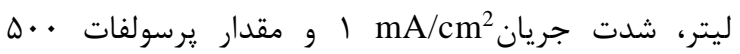

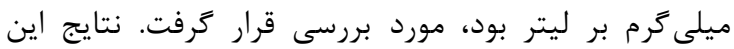

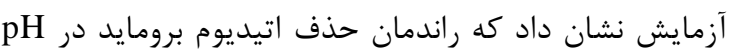

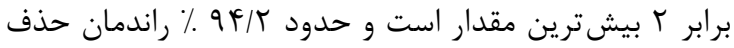

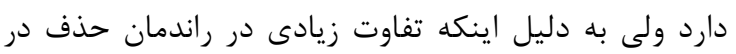

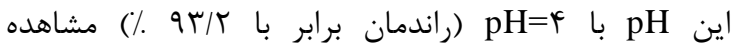

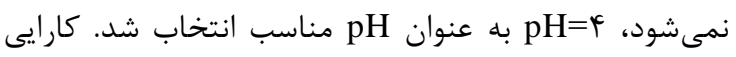

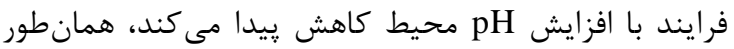

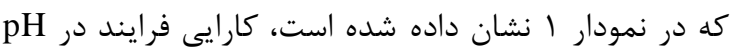

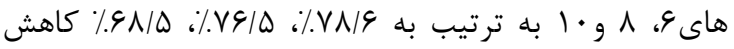
مىيابد. زمان واكنش مناسب طلى اين فرايند . F دقيقه تعيين شد.

\section{اثر تغييرات شدت جريان بر كارايي فرآيند}

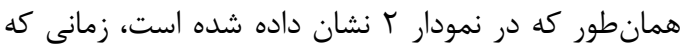

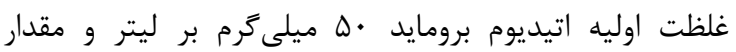

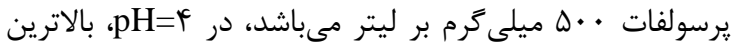

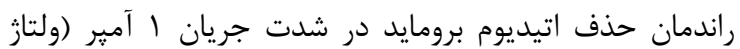

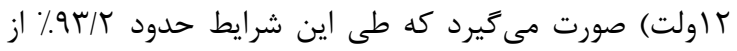

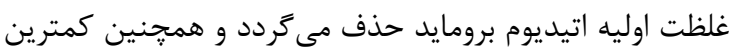

مختلف اتيديوم برومايد ورودى در شرايط مناسبى به دسـت

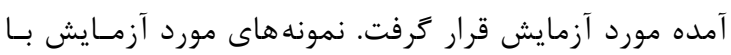

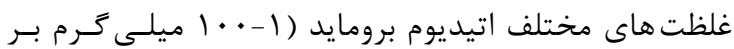

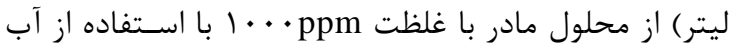

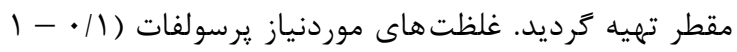

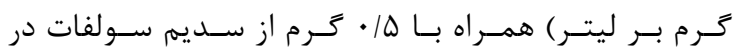
محسـدودهى شـدت جريسان ورودى (

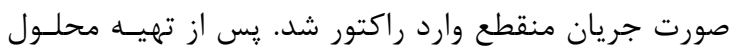

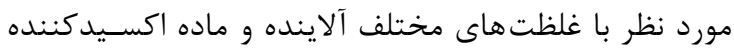

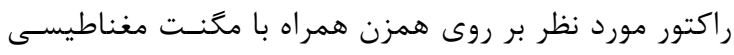

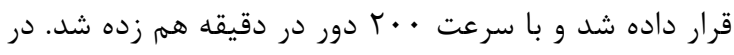

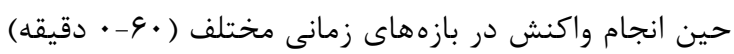

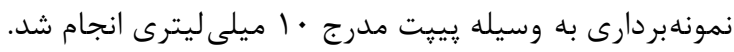
در اين آزمايش جهت حذف لخته هاى تشكيل شده در حين وندين

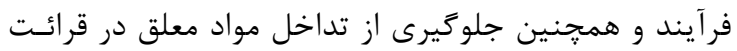

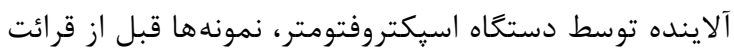
به مدت r دقيقه با سرعت · . . ب دور بر دقيقـه سـانتريفوز شدند.

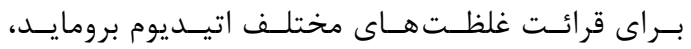

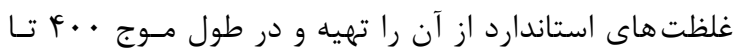

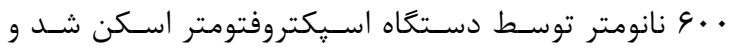

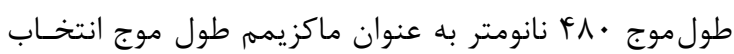

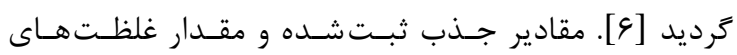

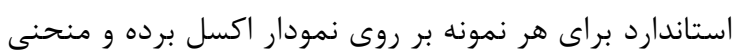
استاندارد آن رسم گرديد.

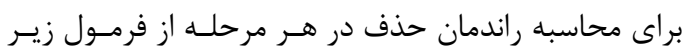
استفاده گرديد:

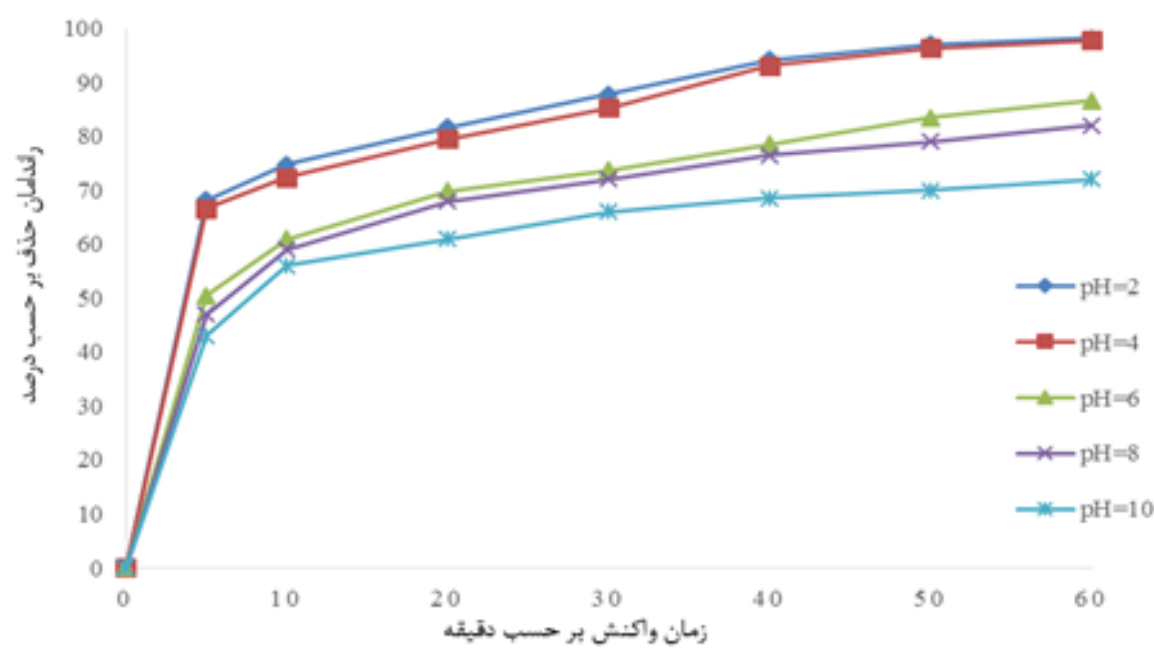

نمودار ا: بررسى تاثير تغييرات pH محيط در ميزان حذف اتيديوم برومايد طى فرايند الكتروشيميايى (غلظت اتيديوم برومايدا/L mg •ه، يرسولفات

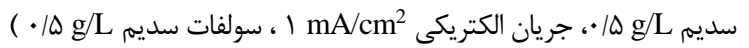




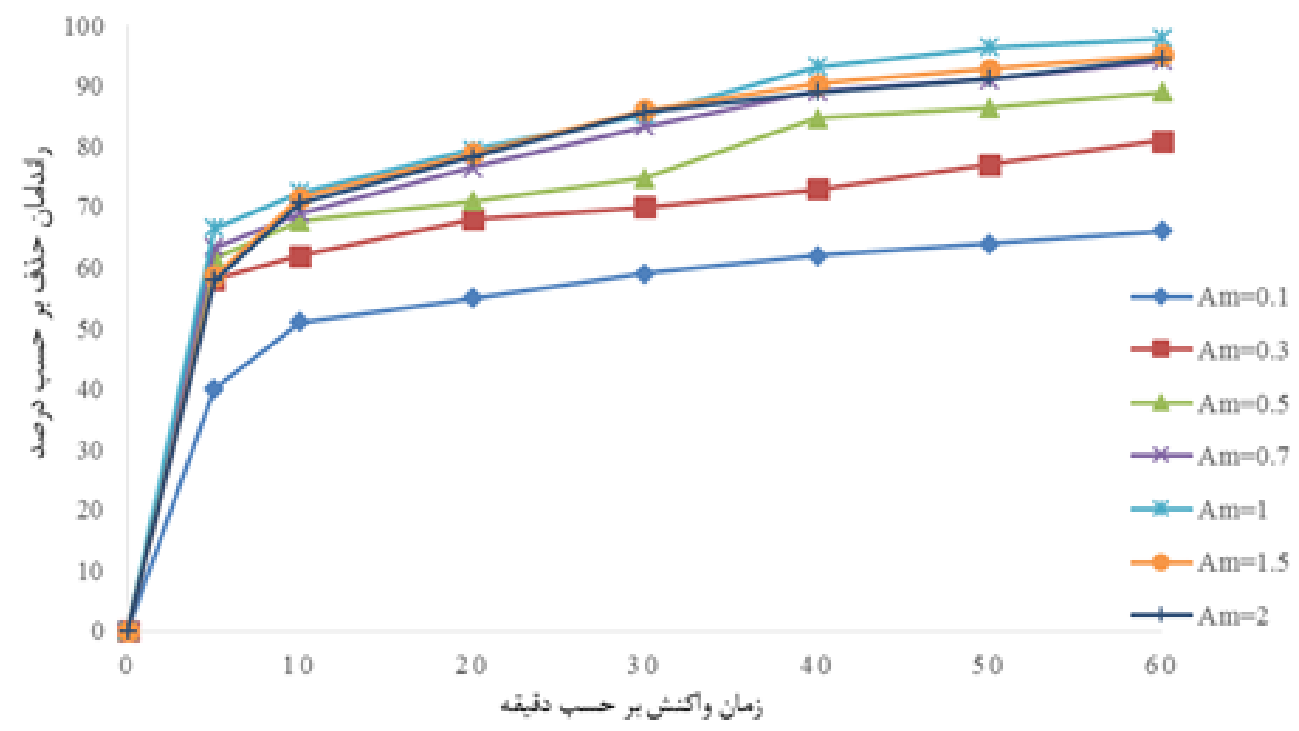

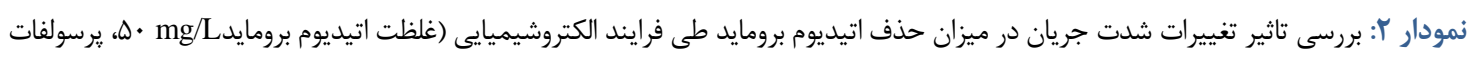

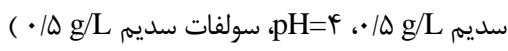

عنوان عامل اصلى توليد راديكال زيرسولفات، تاثير زيادى در

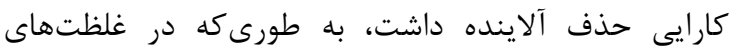

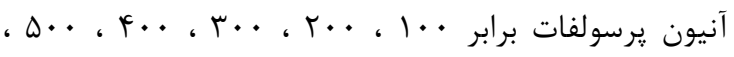

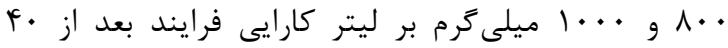
دقيقه به ترتيب

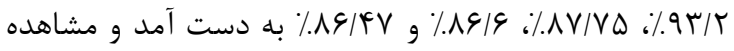

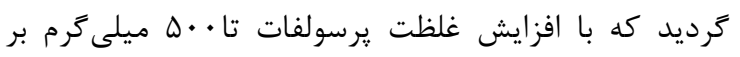

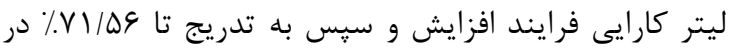

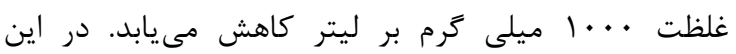

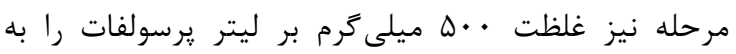

راندمان حذف اتيديوم برومايد در اين فرايند مربوط به شدت

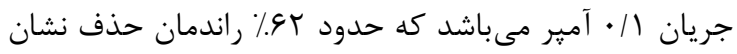
مى دهد. تاثير تغييرات غلظت آنيون يرسولفات بر كارايى فرآيند

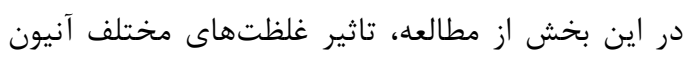

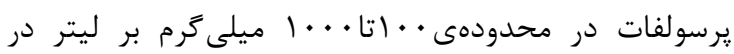

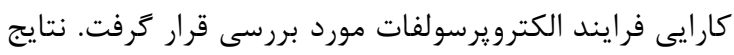

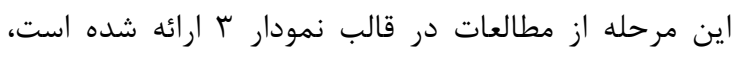

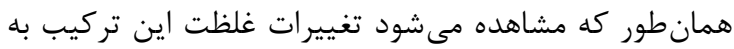

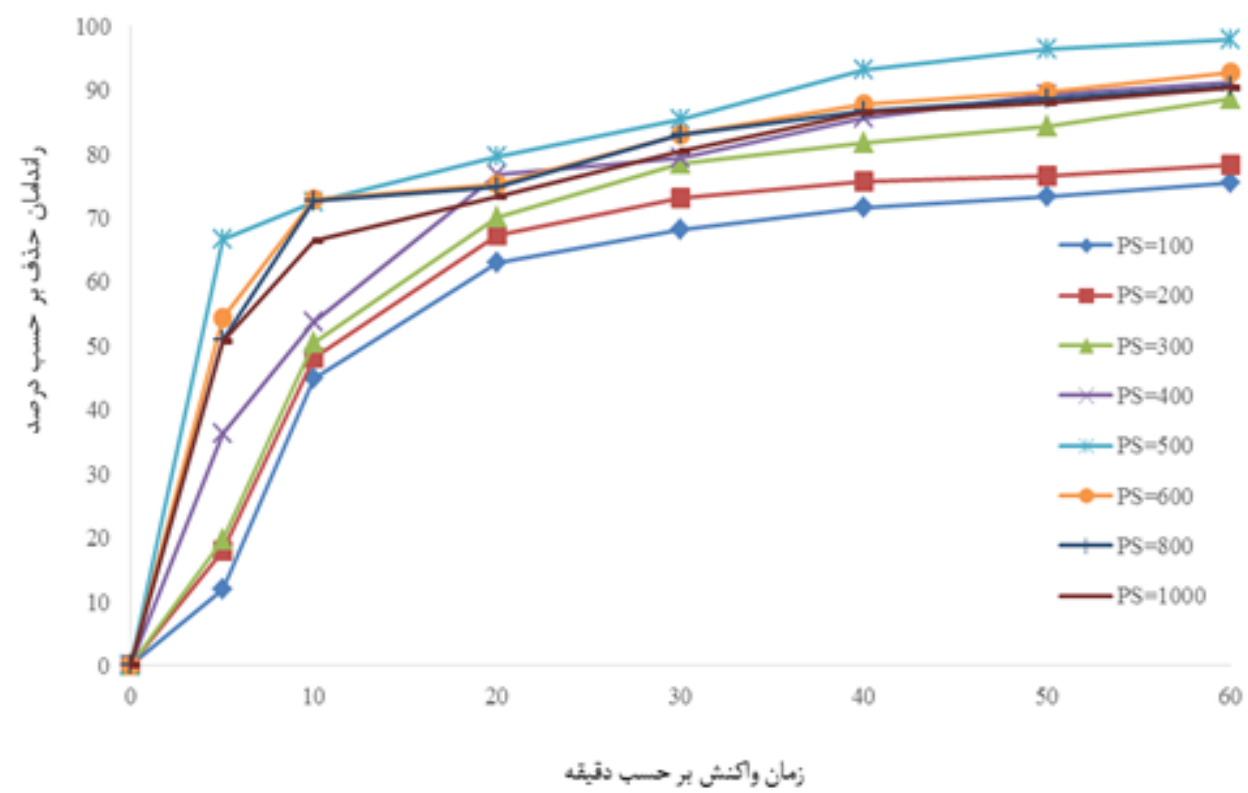

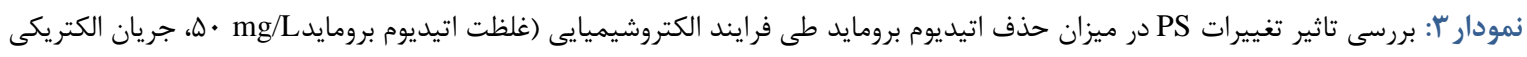

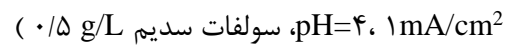


به منظور بررسى و مشخص كردن تاثير همزمان يرسولفات

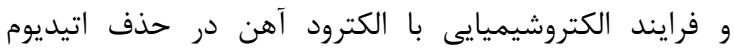

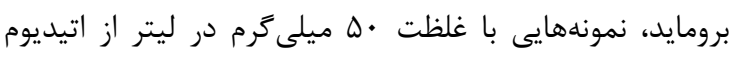

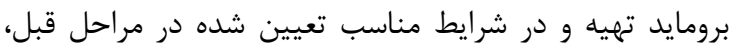

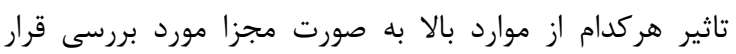

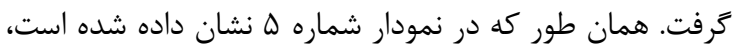

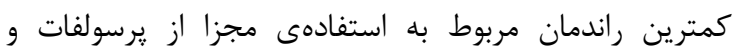
بيشترين راندمان نيز مربوط به استفاده همزمان از فربه فرايند

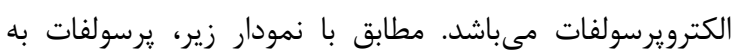

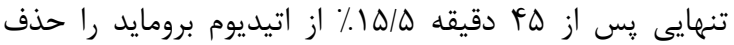

اثر تغييرات غلظت /وليه اتيديوم برومايد بركارايى فرايند

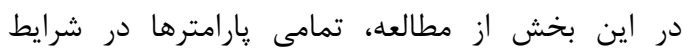
مناسب تنظيم شد و تاثير غلظت اوليه اتيديوم برومايد بر ماربه

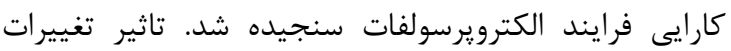

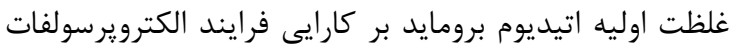

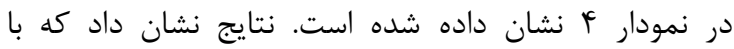

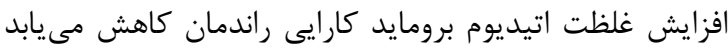

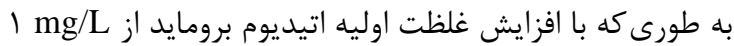

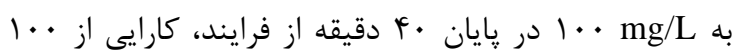

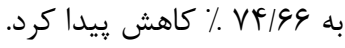

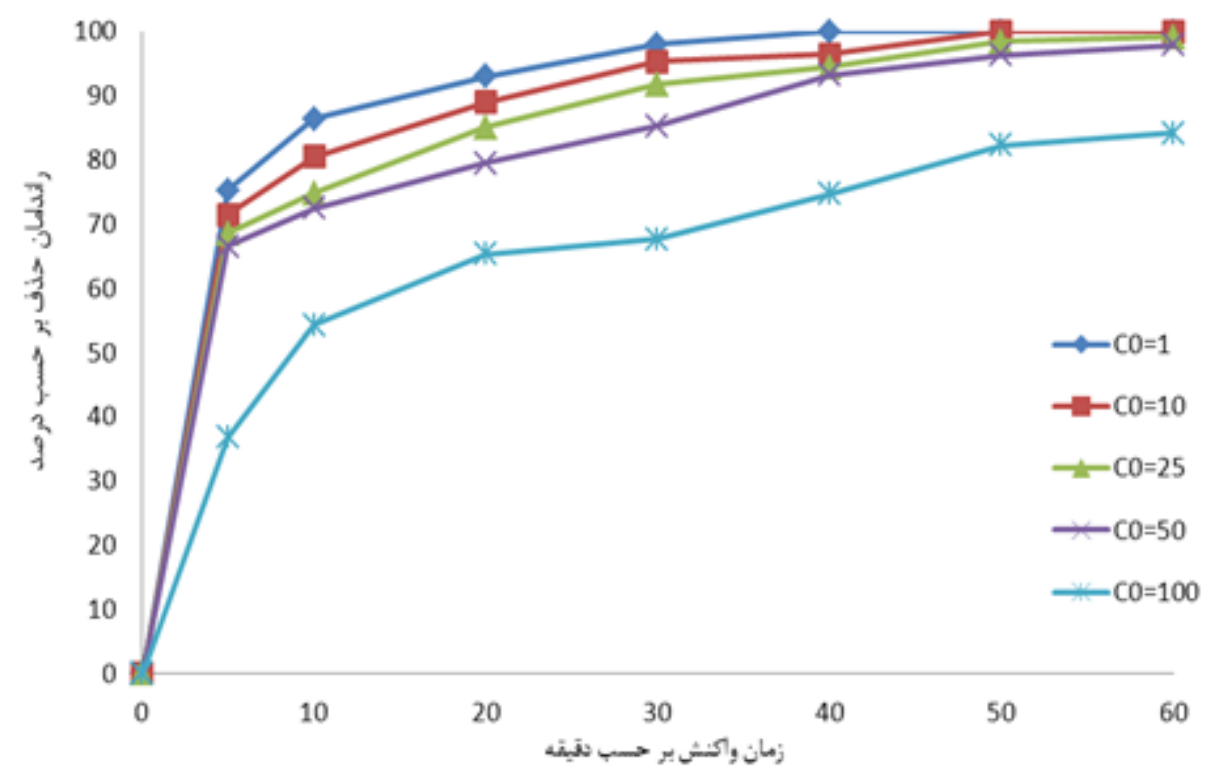

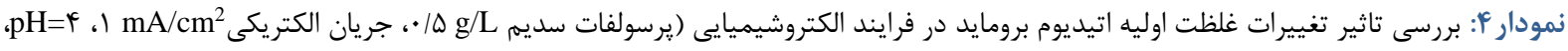
سولفات سديم

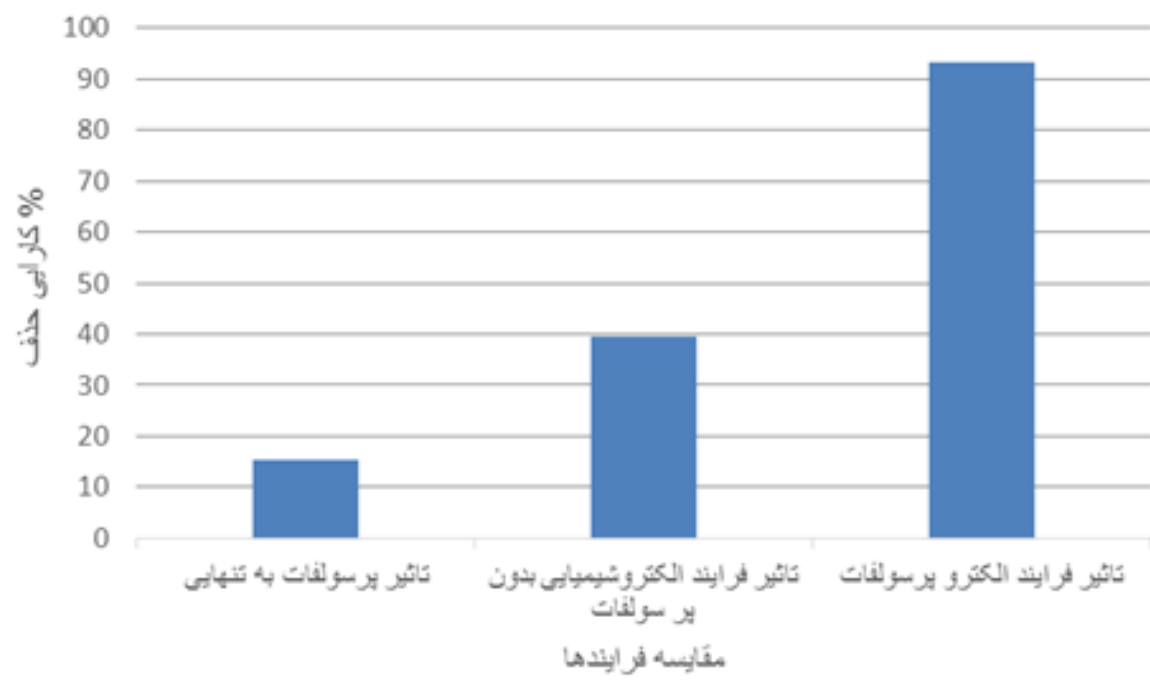

ذمودار ه: بررسى تاثير مجزاى يرسولفات، الكتروشيميايى بدون يرسولفات و فرايند الكترويرسولفات در حذف اتيديوم برومايد (غلظت اتيديوم برومايد

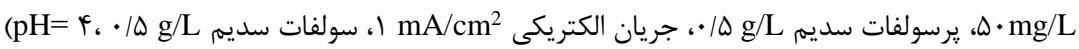


راديكال هاى آزاد مىتوان اشاره كرد (رابطه شماره ه) [11].

$\mathrm{SO}_{4}{ }^{\circ}+\mathrm{H}_{2} \mathrm{O} \leftrightarrow \mathrm{OH}^{\circ}+\mathrm{H}^{+}+\mathrm{SO}_{4}{ }^{2-}$

$\mathrm{SO}_{4}{ }^{\circ}+\mathrm{OH}^{-} \rightarrow \mathrm{OH}^{\circ}+\mathrm{SO}_{4}{ }^{2-}$

$\mathrm{SO}_{4}{ }^{\circ}+\mathrm{OH}^{\circ} \rightarrow \mathrm{H}^{+}+\mathrm{SO}_{4}{ }^{2}$

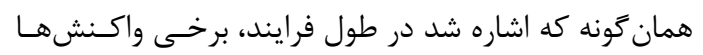

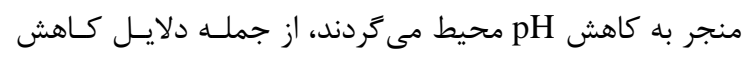

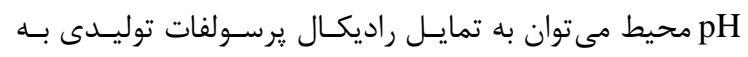

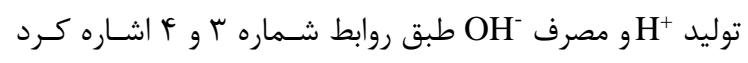

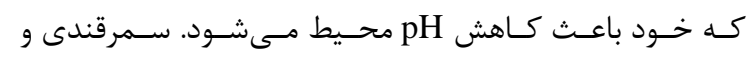

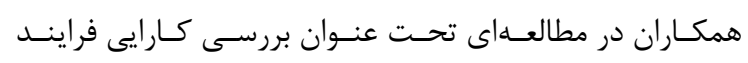

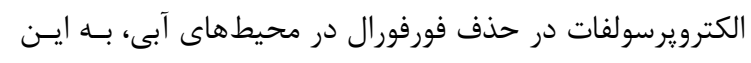

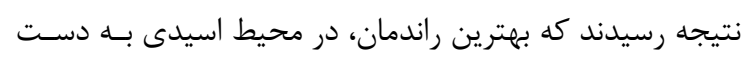

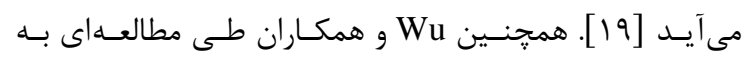

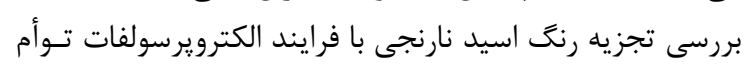

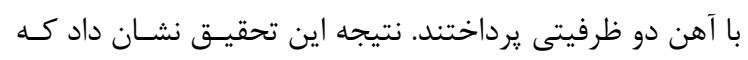

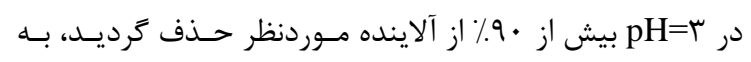

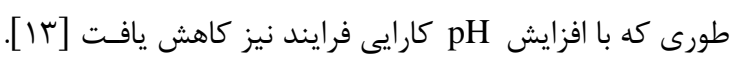

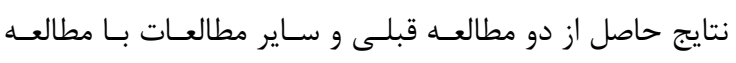

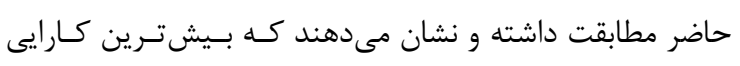
اين فرايند در pH اسيدى اتفاق ميفتد.

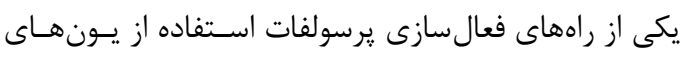

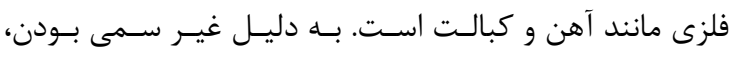

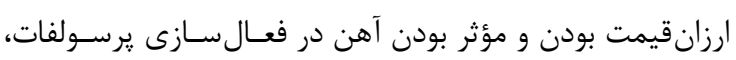

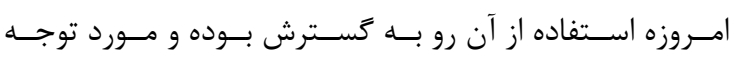

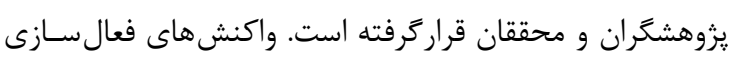

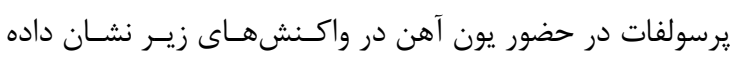

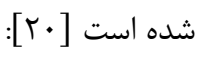

$$
\begin{aligned}
& \mathrm{S}_{2} \mathrm{O}_{8}{ }^{2-}+2 \mathrm{Fe}^{2+} \rightarrow 2 \mathrm{Fe}^{3+}+2 \mathrm{SO}_{4}{ }^{2-} \\
& \mathrm{S}_{2} \mathrm{O}_{8}{ }^{2-}+\mathrm{Fe}^{2+} \rightarrow \mathrm{Fe}^{3+}+\mathrm{SO}_{4}{ }^{2-}+\mathrm{SO}_{4}{ }^{\circ-} \\
& \mathrm{Fe}^{2+}+\mathrm{SO}_{4}{ }^{\circ-} \rightarrow \mathrm{Fe}^{3+}+\mathrm{SO}_{4}{ }^{2-}
\end{aligned}
$$

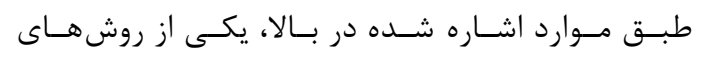

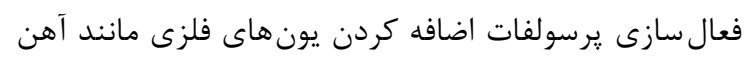

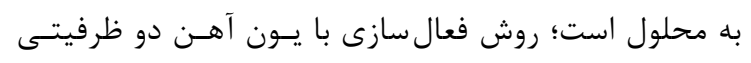

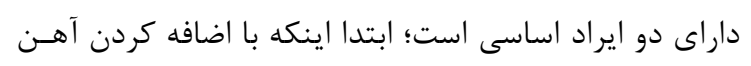

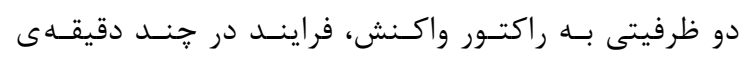

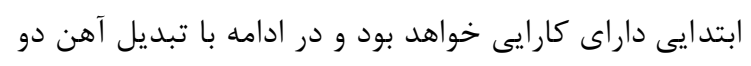

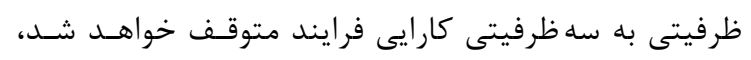

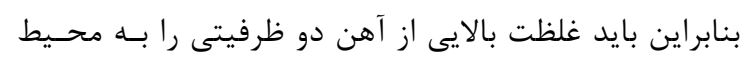

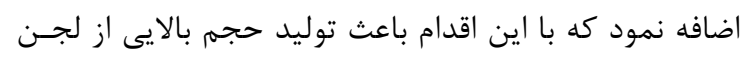

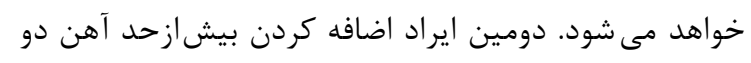

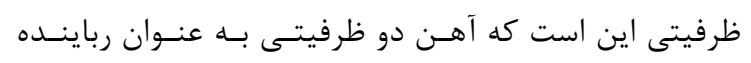

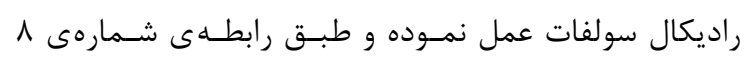

كرده است. همجنين فرايند الكتروشيميايى بدون آنيون

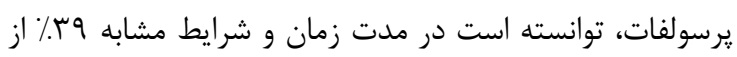
آلاينده مذكور را حذف نمايد.

\section{ميزان كارايى فرايند در كاهش COD در شرايط مناسب}

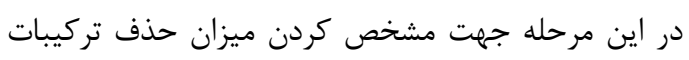

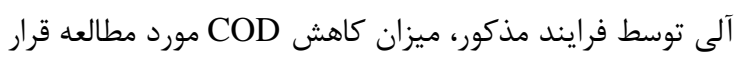

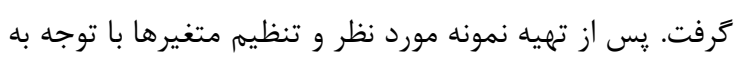

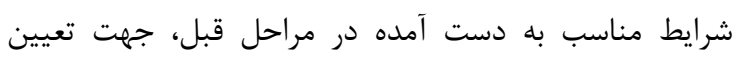

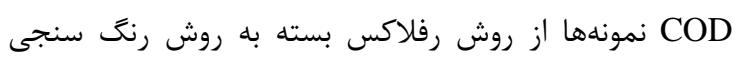

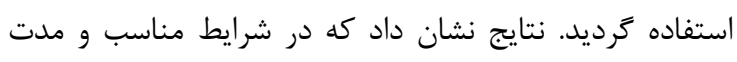

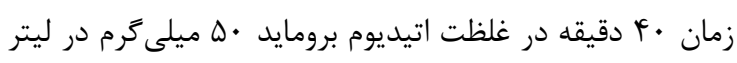

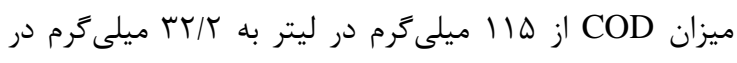

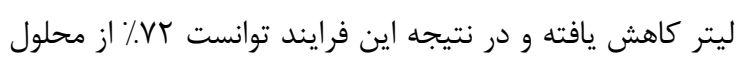
COD

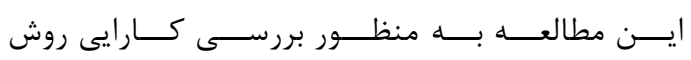

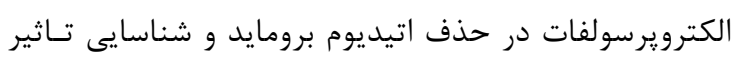

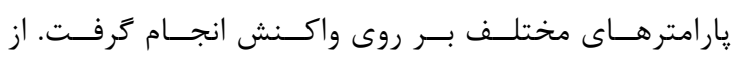

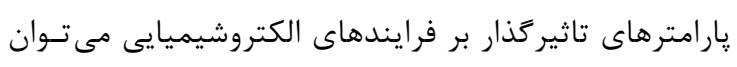

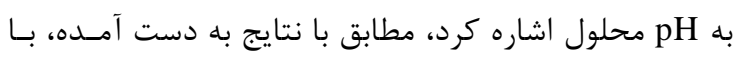

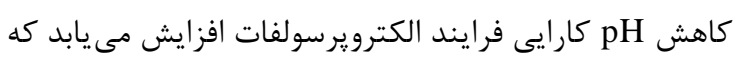

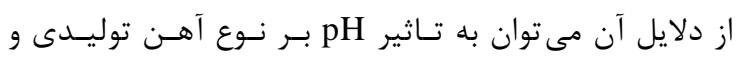

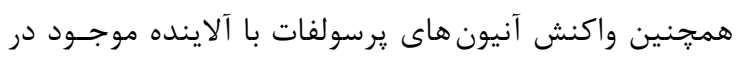

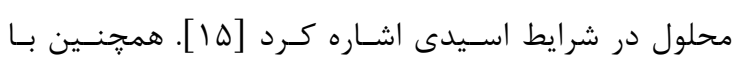

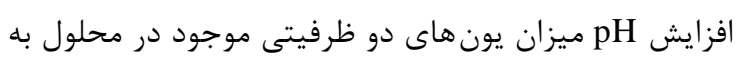

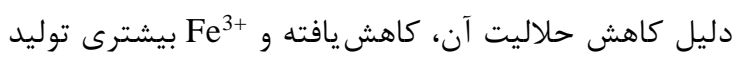

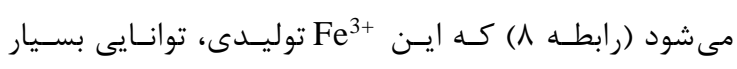

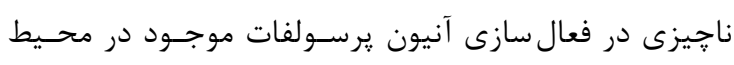

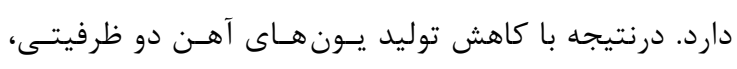

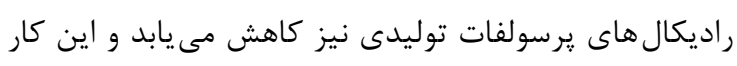

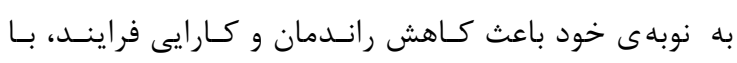

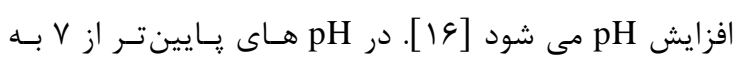

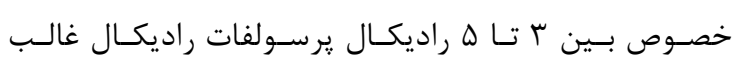

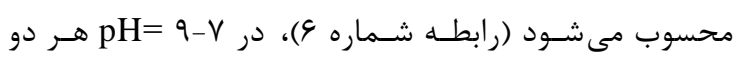

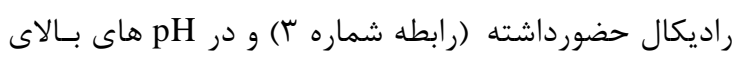

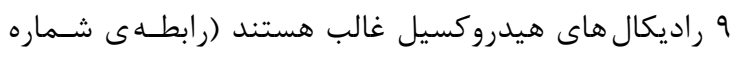

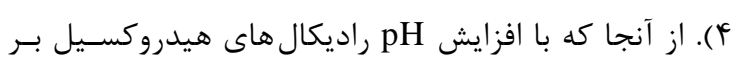

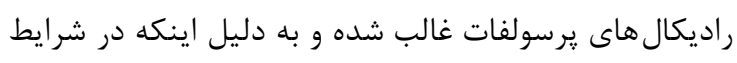

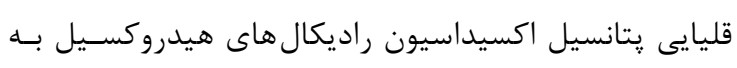

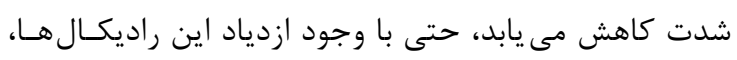

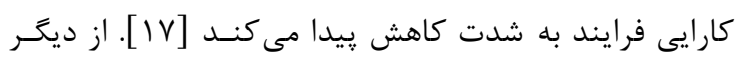

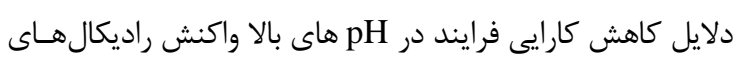

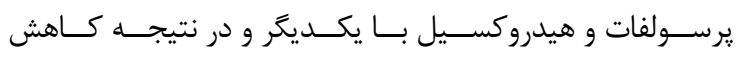


توليد يونهاى فروس در محيط مى شود كه يــون هـاى فـروس

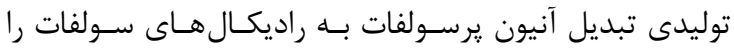

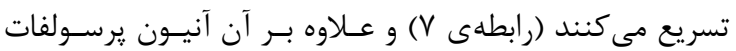

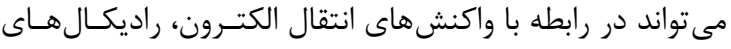

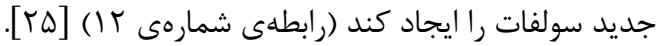

$\mathrm{S}_{2} \mathrm{O}_{8}{ }^{2-}+\mathrm{e}^{-} \rightarrow \mathrm{SO}_{4}{ }^{--}+\mathrm{SO}_{4}{ }^{2-}$

تلفيق فرآيند يرسولفات با فرآيند الكتروشيميايى، به منظور

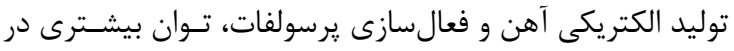

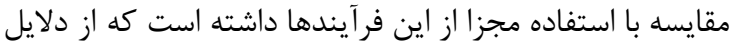

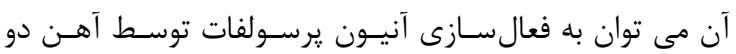

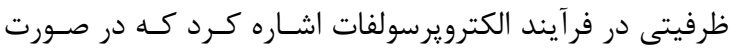

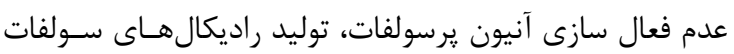

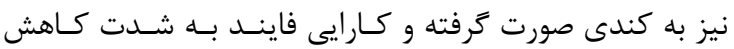

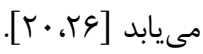

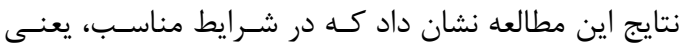

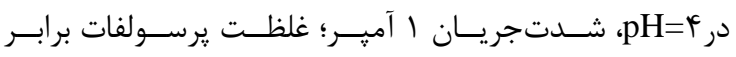

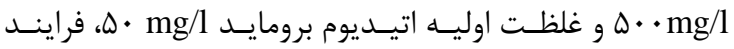

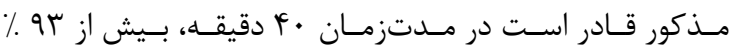

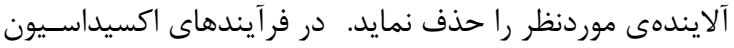

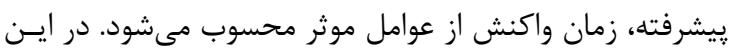

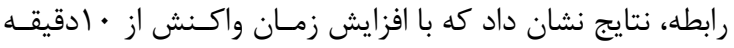

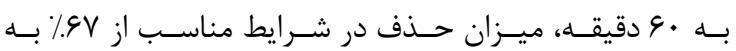

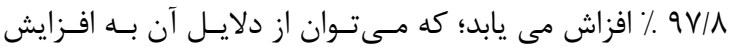

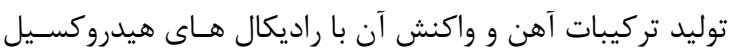

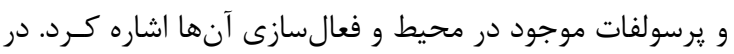

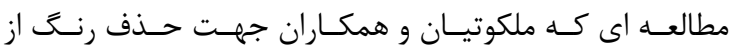
فاضلاب رنكرزى توسط فرايند الكتروفنتون انجام دادند، به ايـن نتيجه رسيدند كه با افزايش زمان واكنش ميزان حذف توسن آلاينـده

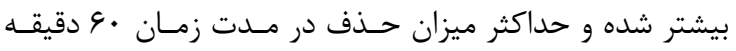

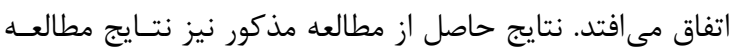

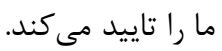

\section{نتيجه تيرى}

نتايج به دسـت آمـده از ايسن تحقيـق نشـان داد كـهـ بـاــا افزايش pH، راندمان فرايند كاهش مى يابد، كارايى رانـدمان

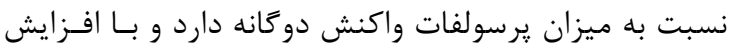

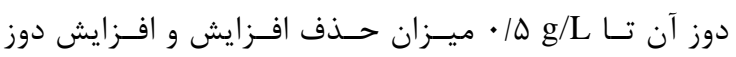

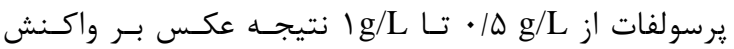

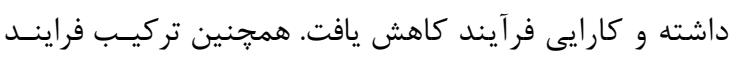

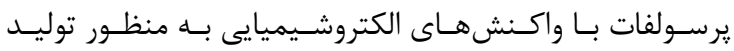

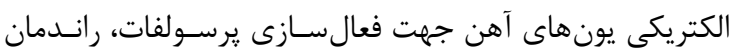

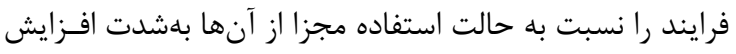

باعث توليد كونه هـاى ديخـر سـولفات مسى شـود كـه قـدرت اكسيداسيون كمترى دارند [باعث] توليد

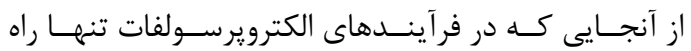

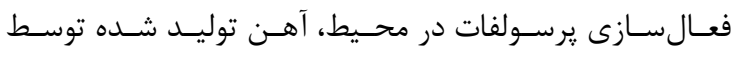

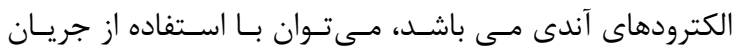

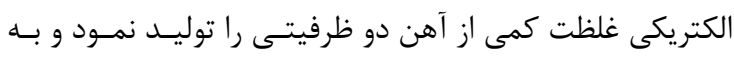

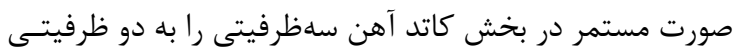

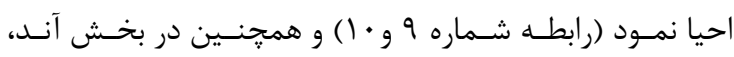
راديكال هيدروكسيل توليد نمود كه به عنوان ديكر اكسيدكننده

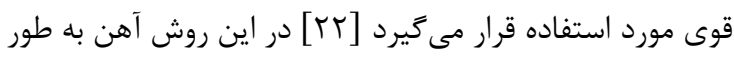

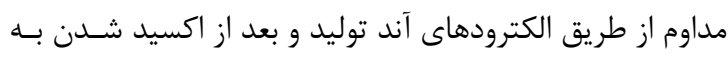

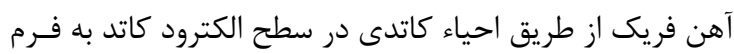

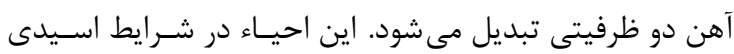

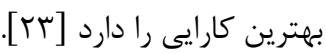

$\mathrm{Fe} \rightarrow \mathrm{Fe}^{2+}+2 \mathrm{e}^{-}$

$\mathrm{Fe}^{3+}+\mathrm{e}^{-} \rightarrow \mathrm{Fe}^{2+}$

يرسولفات بهعنوان منبع توليدكنندهى راديكال هاى سولفات

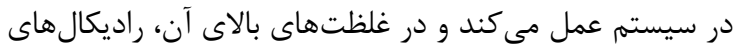

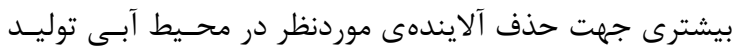

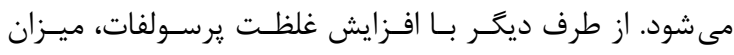

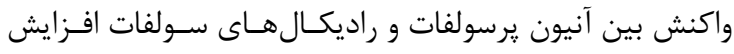

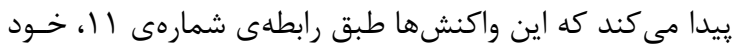

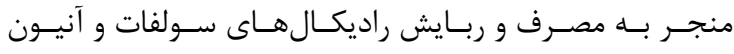

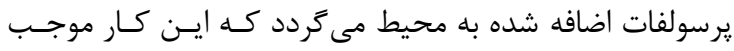

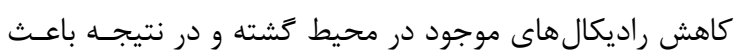

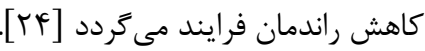

$\mathrm{S}_{2} \mathrm{O}_{8}{ }^{2-}+\mathrm{SO}_{4}{ }^{\cdot-} \rightarrow \mathrm{S}_{2} \mathrm{O}_{8}{ }^{\cdot-}+\mathrm{SO}_{4}{ }^{2-}$

در مطالعه حاضر نيز با افزايش غلظت اوليـه يرســولفات بــه

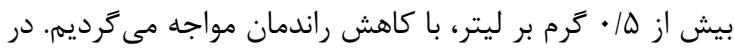

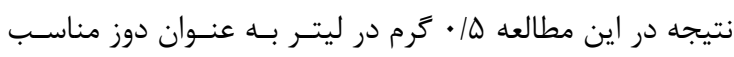
يرسولفات انتخاب كرديد.

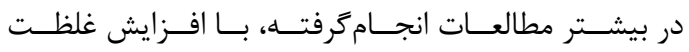

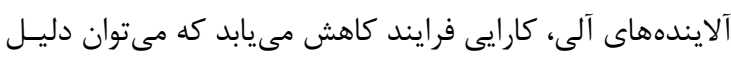

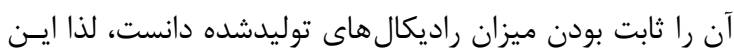

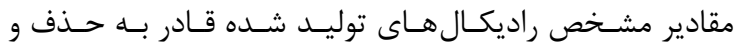

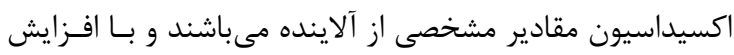

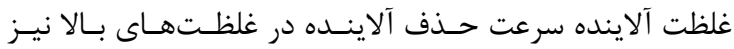

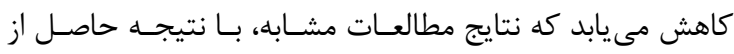

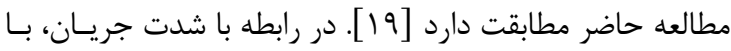

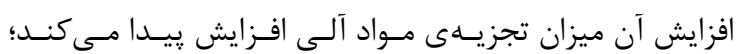

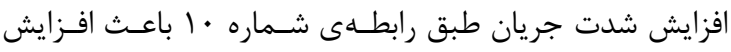




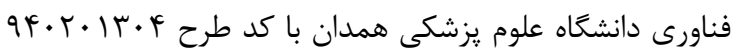

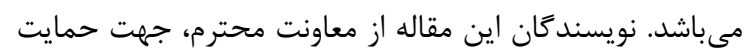

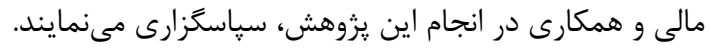

تضاد منافع

اين مطالعه براى نويسندگان هيجز گونه تضاد منافعى نداشته

$$
\begin{aligned}
& \text { مى دهد. بنابراين استفاده از فرايند يرسولفات فعال شده به روش }
\end{aligned}
$$

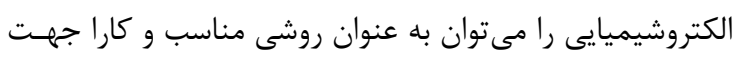

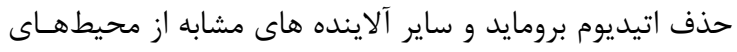

$$
\begin{aligned}
& \text { آبى معرفى كرد. } \\
& \text { تشكر و قلر داذى } \\
& \text { اين مقاله حاصل طرح تحقيقاتى مصوب معاونت تحقيقات و }
\end{aligned}
$$

\section{REFERENCES}

1. Moradi O, Fakhri A, Adami S, Adami S. Isotherm, thermodynamic, kinetics, and adsorption mechanism studies of Ethidium bromide by single-walled carbon nanotube and carboxylate group functionalized single-walled carbon nanotube. J Colloid And Interface Sci. 2013;395:224-9. PMID: 23261335 DOI: 10.1016/j.jcis.2012.11.013

2. Huang Q, Fu WL. Comparative analysis of the DNA staining efficiencies of different fluorescent dyes in preparative agarose gel electrophoresis. Clin Chem Lab Med. 2005;43(8):841-2. PMID: 16201894 DOI:10.1515/CCLM .2005.141

3. Hatami H, Sieyahchehreh M. Investigating the effects of ethidium bromide on some hematological parameters in Cyprinus carpio. J Veterinary Med. 2012;6(1):1-9.

4. Svoboda M, Luskova V, Drastichova J, Žlabek V. The effect of diazinon on haematological indices of common carp (Cyprinus carpio L.). Acta Veterinaria Brno. 2001;70(4):457-65.

5. Sukhumungoon $\mathrm{P}$, Rattanachuay $\mathrm{P}$, Hayeebilan $\mathrm{F}$, Kantachote D. Biodegradation of ethidium bromide by Bacillus thuringiensis isolated from soil. Afr J Microbiol Res. 2013;7(6):471-6. DOI:10.5897/AJMR12.1642

6. Adán C, Bahamonde A, Martínez-Arias A, FernándezGarcía M, Pérez-Estrada L, Malato S. Solar light assisted photodegradation of ethidium bromide over titania-based catalysts. Catalysis Today. 2007;129(1):79-85. DOI:10.1016/j.cattod.2007.06.051

7. Rahmani AR, Shabanloo A, Fazlzadeh M, Poureshgh Y. Investigation of operational parameters influencing in treatment of dye from water by electro-Fenton process. Desalinat Water Treat. 2016;57(51):24387-94. DOI:10.1080/19443994.2016.1146918

8. Samarghandi MR, Shabanloo A, Shamsi K, Mehralipour J, Poureshgh Y. Performance of electrofenton process to remove cyanide from aquatic environments in presence of interfering humic acids. J Health. 2014;4(4):293-303. (Persian)

9. Duffy JE, Carlson EA, Li Y, Prophete C, Zelikoff JT. Agerelated differences in the sensitivity of the fish immune response to a coplanar PCB. Ecotoxicology. 2003;12(14):251-9. PMID: 12739872

10. Tran LH, Drogui P, Mercier G, Blais JF. Coupling extraction-flotation with surfactant and electrochemical degradation for the treatment of $\mathrm{PAH}$ contaminated hazardous wastes. J Hazard Mater. 2009;170(2):1218-26. PMID: 19525064 DOI: 1016/j.jhazmat.2009.05.104

11. Mehralipour J, Leili M, ZolghadrNasab H, Seyed Mohammadi A, Shabanlo A. Efficiency of electro/ $\mathrm{Fe}^{2+} /$ persulfate process in industrial wastewater treatment. J Mazandaran Univ Med Sci. 2015;25(123):137-48. (Persian)

12. Oh SY, Kang SG, Chiu PC. Degradation of 2, 4dinitrotoluene by persulfate activated with zero-valent iron. Sci Total Environ. 2010;408(16):3464-8. PMID: 20471066 DOI:10.1016/j.scitotenv.2010.04.032

13. Wu J, Zhang H, Qiu J. Degradation of Acid Orange 7 in aqueous solution by a novel electro/ $\mathrm{Fe}^{2+} /$ peroxydisulfate process. J Hazard Mater. 2012;215-216:138-45. PMID:
22421343 DOI:10.1016/j.jhazmat.2012.02.047

14. Rahmani AR, Shabanloo A, Mehralipour J, Fazlzadeh M, Poureshgh Y. Degradation of phenol in aqueous solutions using electro-fenton process. Res $\mathbf{J}$ Environ Sci. 2015;9(7):332. DOI: 10.3923/rjes.2015.332.341

15. Waldemer RH, Tratnyek PG, Johnson RL, Nurmi JT. Oxidation of chlorinated ethenes by heat-activated persulfate: kinetics and products. Environ Sci Technol. 2007;41(3):1010-5. PMID: 17328217

16. Ghaedi M, Sadeghian B, Pebdani AA, Sahraei R, Daneshfar A, Duran C. Kinetics, thermodynamics and equilibrium evaluation of direct yellow 12 removal by adsorption onto silver nanoparticles loaded activated carbon. Chem Engin J. 2012;187:133-41. DOI:10.1016/j.cej.2012.01.111

17. ITRC I. Technical and regulatory guidance for in situ chemical oxidation of contaminated soil and groundwater. New York: Council TITaR; 2005.

18. Esplugas S, Gimenez J, Contreras S, Pascual E, Rodríguez M. Comparison of different advanced oxidation processes for phenol degradation. Water Res. 2002;36(4):1034-42. PMID: 11848342

19. Samarghandi MR, Leili M, Harati R, Tarlani Azar M. Efficiency of electro/persulfate process by iron electrode in removing furfural from aqueous solution. J Mazandaran Univ Med Sci. 2014;24(119):95-108. (Persian)

20. Ahmad M, Teel AL, Watts RJ. Mechanism of persulfate activation by phenols. Environ Sci Technol. 2013;47(11):586471. PMID: 23663058 DOI: 10.1021/es400728c

21. Hussain I, Zhang Y, Huang S, Du X. Degradation of pchloroaniline by persulfate activated with zero-valent iron. Chem Engin J. 2012;203:269-76. DOI:10.1016/j.cej. 2012.06.120

22. Zhou L, Zheng W, Ji Y, Zhang J, Zeng C, Zhang Y, et al. Ferrous-activated persulfate oxidation of arsenic (III) and diuron in aquatic system. J Hazard Mater. 2013;263:422-30. PMID: 24220194 Doi:10.1016/j.jhazmat.2013.09.056

23. Lin $\mathrm{H}, \mathrm{Wu} \mathrm{J}$, Zhang H. Degradation of clofibric acid in aqueous solution by an EC/Fe 3+/PMS process. Chem Engin J. 2014;244:514-21. DOI:10.1016/j.cej.2014.01.099

24. Liang C, Wang ZS, Bruell CJ. Influence of $\mathrm{pH}$ on persulfate oxidation of TCE at ambient temperatures. Chemosphere. 2007;66(1):106-13. PMID: 16814844 Doi:10.1016/j.chemosphere.2006.05.026

25. Zhao J, Zhang Y, Quan X, Chen S. Enhanced oxidation of 4-chlorophenol using sulfate radicals generated from zero-valent iron and peroxydisulfate at ambient temperature. Separat Purificat Technol. 2010;71(3):3027. DOI:10.1016/j.seppur.2009.12.010

26. Rahmani A, Mehralipour J, Shabanlo N, Zaheri F, Poureshragh Y, Shbanlo A. Persfromance evaluation of advanced eletrochemical process with the using persulfate in degradation of acid blue 113 from aqueous solutions. J Sabzevar Univ Med Sci. 2014;21(5):797-807. 